\title{
Therapeutic effect of berberine on renal ischemia-reperfusion injury in rats and its effect on Bax and Bcl-2
}

\author{
HAIYA ZHENG, JUN LAN, JINMEI LI and LEILI LV \\ Clinical Laboratory, People's Hospital of Lishui, Lishui, Zhejiang 323000, P.R. China
}

Received January 10, 2018; Accepted June 22, 2018

DOI: $10.3892 /$ etm.2018.6408

\begin{abstract}
This study aimed to investigate the therapeutic effect of berberine on renal ischemia-reperfusion injury in rats and its effect on Bax and Bcl-2. Sixty adult SD rats were randomly divided into four groups: control group A, renal ischemia-reperfusion group $\mathrm{B}$, berberine group $\mathrm{C}$ and berberine + exendin-(9-39) treatment group D. In group A, right kidney was resected and left renal pedicle was separated, but left renal artery was not blocked. Renal ischemia-reperfusion model was established in other groups. Rats in group $\mathrm{C}$ were not subjected to any treatment after model construction. Rats in group C and D were subjected to intraperitoneal injection of berberine 7 days before the experiment. Besides that, intraperitoneal injection of exendin-(9-39) was performed at day 1 and 4 after model construction. Automatic biochemical analyzer was used to measure serum creatinine ( $\mathrm{SCr}$ ) and blood urea nitrogen (BUN). Malondialdehyde (MDA) in renal cortex was measured by enzyme-linked immunosorbent assay and contents of Bax and Bcl-2 in renal tissue were measured by western blot analysis. Apoptosis of rat renal cells was detected by TUNEL assay. The results showed that levels of $\mathrm{SCr}, \mathrm{BUN}, \mathrm{MDA}$ and Bax were significantly higher in group B than in other groups $(\mathrm{P}<0.05)$. Levels of $\mathrm{Bcl}-2$ in group $\mathrm{B}$ were significantly higher than those in group A but significantly lower than those in group C and D. Compared with group A, apoptosis of renal cells was more severe in group B. Compared with group B, apoptosis of renal cells was significantly improved in group $\mathrm{C}$ and $\mathrm{D}$, but was still more severe than that in group A. In conclusion, berberine can effectively improve renal function in rats with renal ischemia-reperfusion injury by inhibiting Bax expression and promoting Bcl-2 expression.
\end{abstract}

Correspondence to: Dr Haiya Zheng or Dr Jun Lan, Clinical Laboratory, People's Hospital of Lishui, 15 Public Street, Liandu, Lishui, Zhejiang 323000, P.R. China

E-mail: zhenghaiyaldd@163.com

E-mail: atomacro@163.com

Key words: berberine, renal ischemia-reperfusion, Bax, Bcl-2, TUNEL method

\section{Introduction}

Ischemia-reperfusion injury (IRI) is caused by blood flow perfusion after organ ischemia, which can bring damages to tissues and organs (1). IRI is a common physiological process in clinical practices. Studies have shown that patients with renal transplantation or renal surgery are likely to be affected by IRI. After renal transplantation, IRI may lead to rejection to cause renal failure, which in turn shortens the survival of patients (2-4). Renal IRI is one of the causes of acute kidney injury. Although great efforts were made to treat this disease, treatment outcomes are still unsatisfactory, and the incidence and mortality are relatively high (5). Therefore, how to reduce the morbidity and mortality is a major task for researchers.

Berberine, also known as jamaicin, is a common type of alkaloids (isoquinolines). The active ingredients are extracted from the roots of the rhizome. Studies have shown that this drug has promising therapeutic effects in the treatment of digestive diseases and diarrhea, but its absorption through oral administration is not satisfactory, and the duration of plasma concentration is short (6,7). Exendin-(9-39), as an antagonist of GLP-1R, can effectively attenuate Nesfatin-1 and delay the emptying of the stomach and reduce the intake of berberine and effectively maintain the retention of berberine (8). In recent years, it has been found that berberine has anti-inflammatory functions and more and more studies confirmed that berberine played a certain regulatory role in inhibiting the body's immune response and anti-apoptosis response (9). In this study, rat model of renal IRI was established to explore the therapeutic effects of berberine in the treatment of renal IRI with the expectation of providing references for clinical treatment.

\section{Materials and methods}

Laboratory animals and materials. A total of 40 healthy male SD rats weighing 250-300 g were purchased from Wuhan MultiSciences (Lianke) Biotech Co., Ltd. (Hangzhou, China). Rabbit polyclonal Bcl-2 antibody (dilution 1/500; cat. no. ab59348) and rabbit monoclonal Bax antibody (dilution 1/500; cat. no. ab32503) were purchased Abcam (Cambridge, MA, USA). Malondialdehyde (MDA) kit was from Beyotime Biotechnology (Jiangsu, China). Exendin-(9-39) kit was purchased from Bachem (Bubendorf, Switzerland). Terminal deoxynucleotidyltransferase-mediated dUTP nick 
end labeling (TUNEL) cell apoptosis kit was purchased from Trevigen (New York, NY, USA).

Animal grouping. Forty adult SD rats were randomly divided into four groups: sham-operation group $\mathrm{A}$, renal ischemia-reperfusion group $\mathrm{B}$, berberine treatment group $\mathrm{C}$ and berberine + exendin-(9-39) treatment group D, 10 rats in each group. Rats were housed in a temperature controlled room $\left(21 \pm 2^{\circ} \mathrm{C}\right)$ on a $12: 12$-h light/dark cycle (lights on at 06:00 a.m.). All rats had free access to water and food. Rats in group A and B were intraperitoneally injected with $2 \mathrm{ml}$ saline from 7 days before surgery. Rats in group C and D were subjected to intraperitoneal injection of berberine $(0.4 \mathrm{mg} / \mathrm{kg} /$ day $) 7$ days before the experiment (berberine powder was dissolved in $2 \mathrm{ml}$ of saline). Besides that, intraperitoneal injection of exendin-(9-39) was performed in group D at day 1 and 4 at a dose of $45 \mu \mathrm{g} / \mathrm{kg} / 3$ days after model construction. In group $\mathrm{A}$, right kidney was resected and left renal pedicle was separated, but left renal artery was not blocked. Renal ischemia-reperfusion model was established in other groups.

Establishment of animal model. Rats were fasted for $12 \mathrm{~h}$ before animal model establishment, but were allowed to access water freely. Intraperitoneal injection of $10 \%$ chloral hydrate $(350 \mathrm{mg} / \mathrm{kg})$ was performed for anesthesia. Rats were fixed and disinfected. An incision was made on the middle of the abdomen, and lateral peritoneum was cut to expose right kidney. Left ureter was protected, and left renal pedicle was separated. A non-destructive vascular clamp was used for left renal artery occlusion until kidneys turned from red to violetblack. Then vascular clamp was removed and the successful establishment of rat model of renal IRI is indicated by the changes of renal color from violet-black to red. The study was approved by the Ethics Committee of People's Hospital of Lishui Animal Center (Zhejiang, China).

Sample collection and testing. Blood samples were collected from the orbital veins of rats before left kidney resection. Before centrifugation at 2,500 x g for $5 \mathrm{~min}$ at $4^{\circ} \mathrm{C}$, level of MDA in plasma was determined according to the instructions of MDA kit, and levels of serum creatinine ( $\mathrm{SCr}$ ) and blood urea nitrogen (BUN) were detected using an automatic biochemical analyzer after left kidney resection was performed, and $500 \mathrm{mg}$ renal tissue was washed three times with $\mathrm{NaCl}$, and stored at $-4^{\circ} \mathrm{C}$. Western blot analysis was used to detect the expression of $\mathrm{Bax}$ and $\mathrm{Bcl}-2$ in renal tissues of rats. Tissue apoptosis was detected by TUNEL assay.

Western blot analysis. Total protein was extracted, quantified, and mixed with buffer. After electrophoresis, transmembrane was performed on ice under $100 \mathrm{~V}$ for $2 \mathrm{~h}$. Membranes were blocked with $5 \%$ skim milk for $1 \mathrm{~h}$, and incubated with primary rabbit polyclonal Bcl-2 antibody (dilution 1:500; cat. no. ab59348) and rabbit monoclonal Bax antibody (dilution 1:500; cat. no. ab32503) overnight. After that, membranes were further incubated with secondary goat anti-rabbit (HRP) IgG antibody(dilution 1:2,000; cat. no. ab6721) at room temperature for $1 \mathrm{~h}$. After washing with TBST, BandScan 5.0 software (Glyko, Inc., Novato, CA, USA) was used to measure gray value of protein bands and calculate the gray ratio.
Table I. Comparison of renal cell apoptosis among 4 groups.

\begin{tabular}{lcc}
\hline Groups & $\mathrm{n}$ & Percentage $(\%)$ \\
\hline A & 9 & $3.40 \pm 1.20$ \\
B & 8 & $57.41 \pm 13.65$ \\
C & 9 & $17.2 \pm 4.2$ \\
D & 10 & $15.1 \pm 2.7$ \\
\hline
\end{tabular}

TUNEL. TUNEL assay kit was used to detect the apoptotic cells in kidney of each group, and the operation was carried out in strict accordance with the instructions of the kit. Cells were counted under optical microscopy. Five visual fields were randomly selected under optical microscope. Apoptosis rate $(\mathrm{AI})=$ total apoptotic cells/total cell number $\mathrm{x} 100 \%$. Determination of apoptotic cells: nuclei of apoptotic renal cells showed yellow or yellow-brown color, and nuclei of normal renal cells showed blue after staining.

Statistical analysis. In this study, SPSS22.0 software package was used to analyze all the data. Measurement data were expressed as mean \pm standard deviation (mean \pm SD), and comparison were performed by ANOVA analysis followed by Least Significant Difference post hoc test. $\mathrm{P}<0.05$ was considered to indicate a statistically significant difference.

\section{Results}

Model construction. In this study, rat model of renal IRI was established. During model construction, 1 rat died in group A, 2 in group B, 1 in group C and none in group D.

Comparison the renal functions among groups. Comparisons of levels of BUN, Scr and MDA among groups showed that levels of BUN, Scr and MDA in group B were significantly increased compared with those in other groups $(\mathrm{P}<0.05)$, while levels of BUN, Scr and MDA were significantly lower in group A than in other groups $(\mathrm{P}<0.05)$. No significant differences in levels of BUN, Scr and MDA were found between groups $\mathrm{C}$ and $\mathrm{D}(\mathrm{P}>0.05)$ (Figs. 1-3).

Comparison of levels of Bax and Bcl-2 among groups. Group C and $D$ pretreated with berberine showed significantly reduced expression level of Bax compared with that in group B, which was not treated with berberine $(\mathrm{P}<0.05)$. In contrast, expression level of Bcl-2 was significantly increased in group C and D compared with group $\mathrm{B}(\mathrm{P}<0.05)$. No significant difference was found between $\mathrm{C}$ and $\mathrm{D}(\mathrm{P}>0.05)$ (Fig. 4).

Comparison of renal cell apoptosis. Apoptosis of rat renal cells was detected by TUNEL method (the positive nucleus was brown and the negative was blue). Apoptosis was found in a small portion of cells in group A $(3.40 \pm 1.20 \%)$. Compared with group A, cell apoptosis was significantly increased in group B $(57.41 \pm 13.65 \%, \mathrm{P}<0.05)$. Compared with group B, apoptosis of renal cells in group $\mathrm{C}$ and $\mathrm{D}$ was significantly improved $(17.2 \pm 4.2$ and $15.1 \pm 2.7 \%, \mathrm{P}<0.05)$. Compared with group A, apoptosis of renal cells in group C and D was 


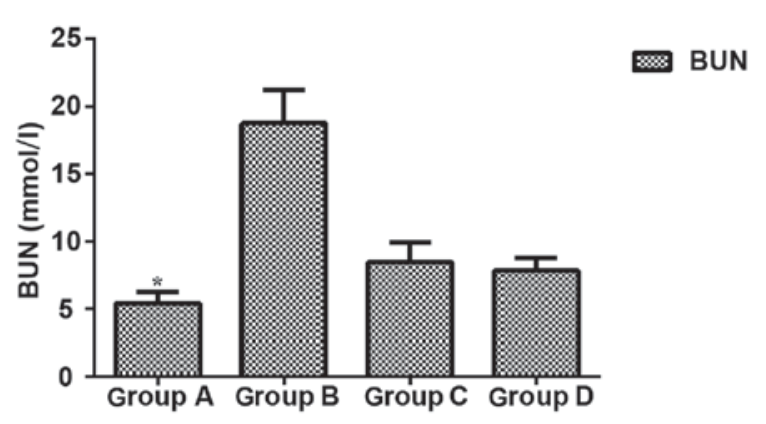

Figure 1. Expression of BUN. Expression levels of BUN in group A were significantly lower than those in group $B(P=0.027)$. Levels of $B U N$ in group A were significantly lower than those in group $\mathrm{C}$ and $\mathrm{D}(\mathrm{P}=0.042$ and $\mathrm{P}=0.045$ ). $\mathrm{BUN}$ expression levels in $\mathrm{C}$ and $\mathrm{D}$ groups were significantly lower than those in $B$ group $(P=0.038$ and $P=0.041)$. There was no significant dif ference between $\mathrm{C}$ and $\mathrm{D}$ groups $(\mathrm{P}>0.05)$. ${ }^{*} \mathrm{P}<0.05$, compared with group $\mathrm{B}$.

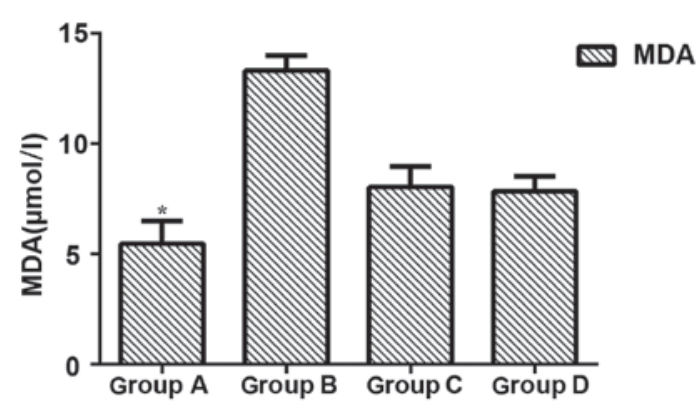

Figure 3. Expression of MDA. Expression levels of MDA in group A were significantly lower than those in group $\mathrm{B}(\mathrm{P}=0.032)$. Expression levels of MDA in group $\mathrm{A}$ and $\mathrm{C}$ were significantly lower than those in group $\mathrm{C}$ $(\mathrm{P}=0.036$ and $\mathrm{P}=0.040)$. There were significant differences between group $\mathrm{B}$ and group $\mathrm{C}$ and $\mathrm{D}(\mathrm{P}=0.044$ and $\mathrm{P}=0.039)$. There was no significant difference between group $\mathrm{C}$ and $\mathrm{D}(\mathrm{P}>0.05)$. ${ }^{*} \mathrm{P}<0.05$, compared with group $\mathrm{B}$.

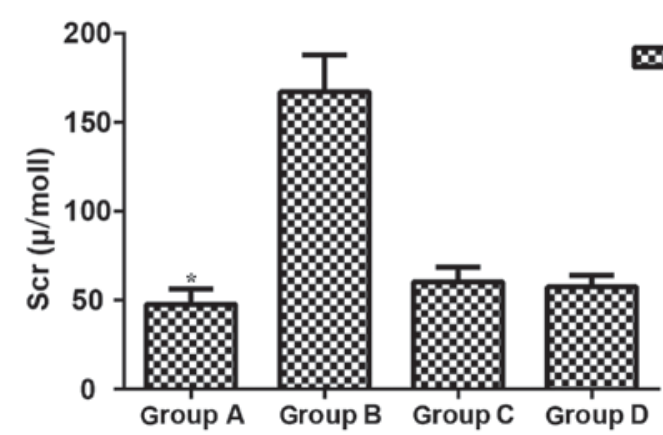

Figure 2. Expression of Scr. Scr expression level in group A was significantly lower than that in group $\mathrm{B}(\mathrm{P}=0.001)$. Scr expression levels in group $\mathrm{A}$ were significantly lower than those in group $\mathrm{C}$ and $\mathrm{D}(\mathrm{P}=0.032$ and $\mathrm{P}=0.035)$. Scr expression levels in $\mathrm{C}$ and $\mathrm{D}$ groups were significantly different from those in $B$ group $(P=0.024$ and $P=0.020)$. There was no significant difference between $\mathrm{C}$ and $\mathrm{D}$ groups $(\mathrm{P}>0.05)$. $\mathrm{P}<0.05$, compared with group $\mathrm{B}$.

significantly increased $(17.2 \pm 4.2$ and $15.1 \pm 2.7 \%, \mathrm{P}<0.05)$. No significant difference was found between group $C$ and $D$ $(\mathrm{P}>0.05)$ (Table I).

\section{Discussion}

Kidney is a high perfusion organ that is highly sensitive to ischemia, hypoxia and reperfusion. IRI is caused by blood flow perfusion after long-term organ ischemia, which can delay recovery of organ functions or even bring damages to tissues and organs (10). Reperfusion may also cause tissue damage, cell apoptosis and necrosis, which has great damage to the tissues and organs of patients (11). Occurrence of renal IRI may cause unsatisfactory treatment outcomes of shock, renal transplantation and cardiopulmonary bypass, and is also a main cause of the failure of renal transplantation (12). At present, the pathogenesis of IRI is still unclear, and mainstream theories include calcium overload, leukocyte action and ATP deficiency (13).

Renal IRI is a complex pathological process with cell necrosis and apoptosis involved (14). Cell necrosis refers to non-programmed cell death mediated by the functions of cell lysates, protein denaturation, and activation of inflammatory factor receptor. Most of the cell necrosis is caused by reversible organ damage (15). Apoptosis is a process of

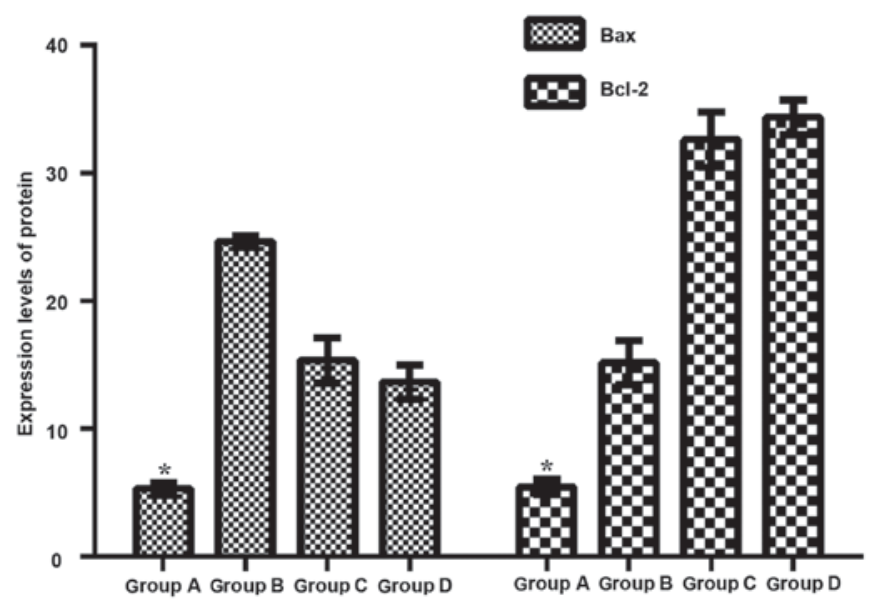

Figure 4. Expression of Bax and Bcl-2. Compared with other groups, expression levels of Bax in group A underwent sham operation decreased significantly $(\mathrm{P}<0.05)$. Bax expression levels in both $\mathrm{C}$ and $\mathrm{D}$ groups pretreated with berberine were significantly lower than those of B group without berberine pretreatment $(\mathrm{P}<0.05)$. Compared with other groups, expression levels of $\mathrm{Bcl}-2$ in group A with sham operation decreased significantly $(\mathrm{P}<0.05)$. On the contrary, there was a significant difference $(\mathrm{P}<0.05)$ between the Bcl-2 expression levels in $\mathrm{C}$ and $\mathrm{D}$ groups and group $\mathrm{B}$ without berberine pretreatment. There was no statistical difference between group $C$ and $D(P>0.05)$. ${ }^{*} \mathrm{P}<0.05$, compared with group $\mathrm{B}$.

programmed cell death that occurs through the regulation of genes, activation of extracellular molecules and external factors (16). Bcl-2, as one of the cytokines with anti-apoptotic function, can inhibit free radicals to induce intracellular calcium overload, causing blocked mitochondrial membrane permeability and caspase activation, thereby inhibiting apoptosis (17). Bax is a class of genes that can promote apoptosis through the regulation of cytokine, and studies have shown that the ratio of $\mathrm{Bax} / \mathrm{Bcl}-2$ can directly reflect cell apoptosis (18).

In this study, rat IRI model was established. Expression levels of Scr and BUN in rats of group A that were treated with saline were significantly lower than those in group B. Berberine and exendin-(9-39) pretreatment significantly reduced the levels of Scr and BUN in group C and D. Scr and BUN are protein metabolites that were discharged through kidneys. Concentrations of Scr and BUN can directly reflect glomerular filtration rate. Concentrations of Scr and BUN 
will increase under renal damage (19). Our study showed that berberine pretreatment can effectively inhibit the occurrence of IRI (19). MDA, as the final products of lipid in oxidation reactions under high levels of oxidative free radicals, can reflect the degree of oxidation reaction (20). Therefore, plasma level of MDA was detected. MDA level was significantly increased in group B compared with other groups, indicating that free radical-induced peroxide is one of the causes of tissue damage. Levels of MDA in group B were significantly higher than those in groups $\mathrm{C}$ and $\mathrm{D}$, which demonstrate that pretreatment with berberine can effectively reduce the expression of MDA. Studies have shown that (21) Bcl-2 family members play pivotal roles in cell apoptosis, and regulation of $\mathrm{Bax}$ and $\mathrm{Bcl}-2$ protein expression can effectively reduce the apoptosis. In this study, western blot analysis results showed that berberine pretreatment significantly reduced the expression levels of Bax protein and increased the expression of Bcl-2 protein in group C and D compared with group B. Studies have shown that (22) Bax expression is upregulated under cell apoptosis, Bax overexpression can promote the cell apoptosis, while Bax expression inhibition can inhibit cell apoptosis. Bcl-2 can bind to Bax to form heterodimers, thereby decreasing the expression of Bax and inhibiting cell apoptosis. TUNEL assay showed that berberine pretreatment significantly improved cell apoptosis in group C and D compared with group B. However, cell apoptosis in group C and D was still more severe than that in group A. Therefore, berberine pretreatment can effectively reduce the severity of IRI, but cannot inhibit its occurrence.

However, this study is still limited by some shortcomings. Sample size is small, and the effects caused by different surgical methods and different ways of anesthesia were not excluded. In addition, only animal experiments were performed, but clinical studies were not included. Those shortcomings will be improved in our future studies.

In conclusion, berberine can effectively improve renal function in rats with renal IRI possibly by inhibiting Bax expression and promoting Bcl-2 expression.

\section{Acknowledgements}

Not applicable.

\section{Funding}

The study was funded by the Scientific Research Fund of Traditional Chinese Medicine in Zhejiang (2015ZA224).

\section{Availability of data and materials}

All data generated or analyzed during this study are included in this published article.

\section{Authors' contributions}

$\mathrm{HZ}$ and JuL designed the study. JiL and LL performed the animal experiments. HZ, JuL and LL analyzed the animal experiment data. All authors read and approved the final manuscript.

\section{Ethics approval and consent to participate}

The study was approved by the Ethics Committee of People's Hospital of Lishui Animal Center (Zhejiang, China).

\section{Patient consent for publication}

Not applicable.

\section{Competing interests}

The authors declare that they have no competing interests.

\section{References}

1. Dorweiler B, Pruefer D, Andrasi TB, Maksan SM, Schmiedt W, Neufang A and Vahl CF: Ischemia-reperfusion injury: Pathophysiology and clinical implications. Eur J Trauma Emerg Surg 33: 600-612, 2007.

2. Eckle T: New 'Guidance' for the treatment of hepatic ischemia reperfusion injury through semaphorins and plexins. Crit Care Med 44: 1623-1624, 2016 .

3. Wu H, Chen G, Wyburn KR, Yin J, Bertolino P, Eris JM, Alexander SI, Sharland AF and Chadban SJ: TLR4 activation mediates kidney ischemia/reperfusion injury. J Clin Invest 117: 2847-2859, 2007.

4. Sung SJ, Li L, Huang L, Lawler J, Ye H, Rosin DL, Vincent IS Le TH, Yu J, Görldt N, et al: Proximal tubule CD73 is critical in renal ischemia-reperfusion injury protection. J Am Soc Nephrol 28: 888-902, 2017.

5. Nezu M, Souma T, Yu L, Suzuki T, Saigusa D, Ito S, Suzuki N and Yamamoto M: Transcription factor Nrf2 hyperactivation in early-phase renal ischemia-reperfusion injury prevents tubular damage progression. Kidney Int 91: 387-401, 2017.

6. Zou K, Li Z, Zhang Y, Zhang HY, Li B, Zhu WL, Shi JY, Jia Q and Li YM: Advances in the study of berberine and its derivatives: A focus on anti-inflammatory and anti-tumor effects in the digestive system. Acta Pharmacol Sin 38: 157-167, 2017.

7. Li D, Zheng J, Hu Y, Hou H, Hao S, Liu N and Wang Y: Amelioration of intestinal barrier dysfunction by berberine in the treatment of nonalcoholic fatty liver disease in rats. Pharmacogn Mag 13: 677-682, 2017.

8. Haufe TC, Gilley AD, Goodrich KM, Ryan CM, Smithson AT, Hulver MW, Liu D and Neilson AP: Grape powder attenuates the negative effects of GLP-1 receptor antagonism by exendin-3 (9-39) in a normoglycemic mouse model. Food Funct 7 : 2692-2705, 2016.

9. Zhao GL, Yu LM, Gao WL, Duan WX, Jiang B, Liu XD, Zhang B, Liu ZH, Zhai ME, Jin ZX, et al: Berberine protects rat heart from ischemia/reperfusion injury via activating JAK2/STAT3 signaling and attenuating endoplasmic reticulum stress. Acta Pharmacol Sin 37: 354-367, 2016.

10. Koo TY, Lee JG, Yan JJ, Jang JY, Ju KD, Han M, Oh KH, Ahn C and Yang J: The P2X7 receptor antagonist, oxidized adenosine triphosphate, ameliorates renal ischemia-reperfusion injury by expansion of regulatory T cells. Kidney Int 92: 415-431, 2017.

11. Linkermann A, Bräsen JH, Darding M, Jin MK, Sanz AB, Heller JO, De Zen F, Weinlich R, Ortiz A, Walczak H, et al: Two independent pathways of regulated necrosis mediate ischemia-reperfusion injury. Proc Natl Acad Sci USA 110: 12024-12029, 2013.

12. Thorenz A, Chen R, Rong S, Klemann C, Haller H, Braesen JH, Klos A and Gueler F: C5aR2 deficiency improves renal regeneration after renal ischemia reperfusion injury and in kidney transplantation in mice. FASEB J 31: 1030.9-1030.9, 2017.

13. Nogueira MA, Coelho AM, Sampietre SN, Patzina RA, Pinheiro da Silva F, D'Albuquerque LA and Machado MC: Beneficial effects of adenosine triphosphate-sensitive $\mathrm{K}^{+}$channel opener on liver ischemia/reperfusion injury. World J Gastroenterol 20: 15319-15326, 2014.

14. Noh MR, Kim JI, Han SJ, Lee TJ and Park KM: C/EBP homologousprotein (CHOP) gene deficiency attenuates renal ischemia/reperfusioninjury in mice. Biochim Biophys Acta 1852: 1895-1901, 2015. 
15. Lau A, Wang S, Liu W, Haig A, Zhang ZX and Jevnikar AM: Glycyrrhizic acid ameliorates HMGB1-mediated cell death and inflammation after renal ischemia reperfusion injury. Am J Nephrol 40: 84-95, 2014.

16. Lin M, Li L, Li L, Pokhrel G, Qi G, Rong R and Zhu T: The protective effect of baicalin against renal ischemia-reperfusion injury through inhibition of inflammation and apoptosis. BMC Complement Altern Med 14: 19, 2014.

17. Edlich F and Martinou JC: Bcl-2 protein interplay on the outer mitochondrial membrane. In: Mitochondria and Cell Death. Springer, New York, pp69-83, 2016.

18. Liu Y, Wang L, Du Y, Chen Z, Guo J, Weng X, Wang X, Wang M, Chen D and Liu X: Effects of apigenin pretreatment against renal ischemia/reperfusion injury via activation of the JAK2/STAT3 pathway. Biomed Pharmacother 95: 1799-1808, 2017.

19. Schrezenmeier EV, Barasch J, Budde K, Westhoff T and Schmidt-Ott KM: Biomarkers in acute kidney injury - pathophysiological basis and clinical performance. Acta Physiol (Oxf) 219: 554-572, 2017
20. Chatterjee PK, Brown PA, Cuzzocrea S, Zacharowski K, Stewart KN, Mota-Filipe H, McDonald MC and Thiemermann C: Calpain inhibitor-1 reduces renal ischemia/reperfusion injury in the rat. Kidney Int 59: 2073-2083, 2001.

21. Shen S, Zhou J, Meng S, Wu J, Ma J, Zhu C, Deng G, Liu D, Shen $S$ and Zhou J: The protective effects of ischemic preconditioning on rats with renal ischemia-reperfusion injury and the effects on the expression of Bcl-2 and Bax. Exp Ther Med 14: 4077-4082, 2017.

22. Decuypere JP, Ceulemans LJ, Agostinis P, Monbaliu D, Naesens M,Pirenne J and Jochmans I: Autophagy and the kidney: Implications for ischemia-reperfusion injury and therapy. Am J Kidney Dis 66: 699-709, 2015.

(i) () () This work is licensed under a Creative Commons EY Attribution-NonCommercial-NoDerivatives 4.0 International (CC BY-NC-ND 4.0) License. 